\title{
Uncovering early indicators of fixation during the concept development stage of children's design processes
}

\author{
Alice Schut $^{1}$ D $\cdot$ Remke Klapwijk $^{1} \cdot$ Mathieu Gielen $^{2} \cdot$ Fenne van Doorn $^{3}$. \\ Marc de Vries ${ }^{1}$
}

Accepted: 22 May 2019 / Published online: 28 May 2019

(C) The Author(s) 2019

\begin{abstract}
In this paper, we explore the early indicators of design fixation occurring during the concept development stage of children's design processes. This type of fixation, which we named: concept fixation, causes a blind adherence to the current (possibly unfavourable) state of a design idea. Its occurrence hampers the creative thinking processes present in a design process, which in turn stagnates the development of initial design ideas into final designs. Until now, research on design fixation has mainly focussed on creative idea generation in the early phases of the design process through analysing (intermediate) design ideas and completed artefacts. However, children's fixation behaviours might be identified at an earlier moment through the conversations that take place in the classroom about their design ideas. To this end, we present a case study in which we explored early indicators of concept fixation of a group of 24 primary school children (ages 9-11) carrying out a co-design project. Fixation was observed through the manner in which the design teams responded to questions and comments from their peers and the client. Four categories of response behaviours indicating concept fixation emerged from the verbal data, namely: 'band-aids', 'already-in-there', 'question-not-relevant' and 'it's-not-possible'. We expect that the indicators will be helpful in identifying concept fixation during the design process, especially in an educational context. The process of identification of fixation, and reflecting on it, creates awareness. This is considered as an important step by professional designers towards guarding oneself from fixation episodes in future projects, and thus being more creative.
\end{abstract}

Keywords Convergent thinking $\cdot$ Creativity $\cdot$ Design fixation $\cdot$ Divergent thinking $\cdot$ D\&T education

Alice Schut

a.schut@tudelft.nl

1 Faculty of Applied Sciences, Science Education and Communication, Room C116, Delft University of Technology, Lorentzweg 1, 2628 CJ Delft, The Netherlands

2 Industrial Design, Delft University of Technology, Delft, The Netherlands

3 The Hague University of Applied Sciences, The Hague, The Netherlands 


\section{Introduction}

There are not many aspects of human cognition that are more intriguing or mystifying than creativity. It could be argued that it is the highest level of our cognitive abilities and that all of our advances have been accomplished through it. Although often believed that creativity is something a lucky few among us just inherently possess, it can be, to some extent, found in everyone (Guilford 1987). Additionally, evidence suggests that it can be trained (Scott et al. 2004). Within the context of primary education, creativity is progressively seen as a skill of great value. Design and technology-related subjects offer great opportunities to stimulate and develop the creative abilities of children (Lewis 2005, 2009; Rutland and Barlex 2008; Thijs et al. 2014; Voogt and Roblin 2012). Designing is argued to correspond closely with the basic nature of creativity (Barlex 2007). It can offer conditions that promote creativity due to its open-ended nature, in which design problems are ill-structured and solutions are not defined in advance (Dorst 2003; Lewis 2005). When solving an ill-structured design problem, children cannot fall back on any existing formula in which a 'right' answer exists. They need to resort to creative thought processes to generate and develop solutions (Lewis 2009).

More and more focus is put on the importance of providing opportunities for children to behave creatively while taking part in design subjects like Design and Technology (D\&T) (Atkinson 2000; Benson and Lawson 2017; Benson and Lunt 2011; Klapwijk and Holla 2018; Lewis 2005). However, research has also shown that behaving creatively is not always easy for children. This is due to various external reasons, such as the available teaching methods, teacher beliefs (Cropley and Cropley 2010; Thijs et al. 2014) and examination requirements (Greven and Letschert 2006) and internal reasons, such as children's personality and their cognitive abilities (Atkinson 2000; Lewis 2005). Another contributing factor is the occurrence of design fixation-a sort of block in creative thinking processes - in pupils participating in design classes (McLellan and Nicholl 2009; Nicholl and Mclellan 2007a, b; 2008). It shows that behaving creatively doesn't always come naturally to children and that the context is of influence on the development of creative thinking (Cropley and Urban 2000). There is a need for research that focuses on how children can develop their creative abilities through design-related subjects and how they can best be guided during this process. An essential part of this is to investigate the problem of design fixation in children, which will be the focus of this case-study.

Creativity is often defined as the ability to produce an output that is both novel (original) and appropriate (relevant for the problem at hand) (Amabile 1996; Cropley and Cropley 2010; Guilford 1967). When children work towards a creative output, creative thinking processes play an essential role. Creative thinking involves the continuous shifting between two cognitive processes: divergent (DT) and convergent (CT) thinking (Finke et al. 1992; Goldschmidt 2014, 2016). Ideation and evaluation will follow each other continuously. When designing, these two modes of thinking are needed throughout the whole process. Design fixation, commonly known as the blind adherence to a limited set of ideas (Jansson and Smith 1991), may however occur and hamper the continuous cycles of divergent and convergent thinking. A great body of literature describes that adult designers often have great difficulty to avoid or overcome design fixation and a few studies identified this problem also in secondary education (McLellan and Nicholl 2009; Nicholl and Mclellan 2007a, b). Ultimately, the occurrence of design fixation results in less creative and less complete designs, e.g. not all the design criteria or needs of the user and context have been met. 
Design fixation is commonly identified by analysing design ideas and produced artefacts (Sio et al. 2015; Vasconcelos and Crilly 2016). In the classroom, design fixation has for example been identified by teachers at the end of a design project through 'stereotypical' designs that are made by the children (Nicholl and Mclellan 2007a, b, 2008). However, knowing that design fixation has occurred at the end of design projects is usually not helpful in moving novice designers forward. From a pedagogical viewpoint, there is a need to make design fixation visible during the design process. As this would give children an opportunity to overcome a creative hurdle in the specific design project at hand. In addition, the increased understanding of their own fixation will also help them strengthen their creative thinking in the long run.

In this study, we will therefore look for ways to identify fixation in the design process, through other methods than analysing the design outputs at the end of a design project. When designing in teams, talk is used as one of the main principles in constructing and developing design ideas. Through talk, a shared understanding of a design idea can be reached and agreements and compromises can be made (Fox-Turnbull 2018). Therefore, the conversations held while designing may offer opportunities for the identification of design fixation. In the case study presented here, we observed a group of primary school children (ages 9-11) carrying out a design project. We will take a closer look at the conversations that took place between the children, their peers, and the client to identify the fixation moments. We are especially interested in the occurrence of fixation when design ideas get developed during the later stages of their design processes. Our explorative research question is: How might design fixation be expressed in the conversations of children during the concept development stage of the design process?

\section{Theoretic framework}

In this section, we elaborate on creative thinking in the context of the concept development stage and address problems that may arise. First, we discuss the role of DT and CT during the concept development stage of the design process. Subsequently, a common factor stagnating creative thinking when designing, design fixation, is explained in the context of concept development and D\&T education.

\section{Creative thinking during concept development}

Designing is an inherently creative activity and a typical case of creative thinking (Goldschmidt 2014; Howard et al. 2008). Throughout the whole design process there is a continuous shifting between divergent (DT) and convergent (CT) thinking, through which ideation and evaluation follow each other continuously (Finke et al. 1992; Goldschmidt 2014, 2016; Isaksen et al. 2010; Tassoul 2009). The terms 'DT' and 'CT' were first mentioned by Guilford in the 1950s (Guilford 1956, 1962). DT entails the generation of novelty, which is commonly thought to go hand in hand with the ability to see lots of possible answers and interpretations to a problem or issue. CT entails the evaluation of this novelty, which deals with analysing and selecting the 'best' answer to a problem or issue. As the ability to separate and alternate between DT and CT is considered extremely valuable when developing creative solutions (Guilford 1967; Howard-Jones 2002; Isaksen et al. 2010; Tassoul 2009), it is important for children to practice this continuous alteration throughout the whole design process. 
In the Creative Problem Solving (CPS) tradition idea development is explained as the stage in which an initial idea is selected and the focus lies on perfecting promising option(s) in order to end up with the best design possible (Isaksen et al. 2010; Tassoul 2009). Figure 1 shows Tassoul's adaptation of the CPS model in which this idea development is part of the last stage, named: 'Concept Development'. Usually, the idea that is initially selected does not have much detail yet, and not all criteria of the design problem at hand are covered. Further elaboration is needed. In addition, there can be unforeseen shortcomings within the idea that only come to light later in the design process. To identify these various sub-problems critical reflection and evaluation (CT) of the design idea is needed. When designers work on these sub-problems they need new input in the form of ideas (DT) and this, in turn, leads to the selection of one of these ideas (CT) to solve the sub-problem at hand. If too many unsolvable sub-problems arise, the decision can be made to reject the idea and start over, or merge elements of the idea with another idea.

Tassoul acknowledges the equal importance of DT and CT, and the necessity of the alteration between the two in order to fully develop ideas (Tassoul 2009). The importance of these iterative processes are made visible by three spiralling lines in the model (see Fig. 1). As the number of alternations of DT and CT increase, the design process becomes more sophisticated (Mioduser and Kipperman 2002). Ideally, design ideas keep on developing and continuously improving in order to manifest into the ultimate design, which embodies all the desired design requirements. Here we focus on the concept development stage in order to gain insight into one of the hurdles in children's creative thinking when they develop their design ideas, namely design fixation.

Fig. 1 The creative problem solving (CPS) model (Tassoul 2009)

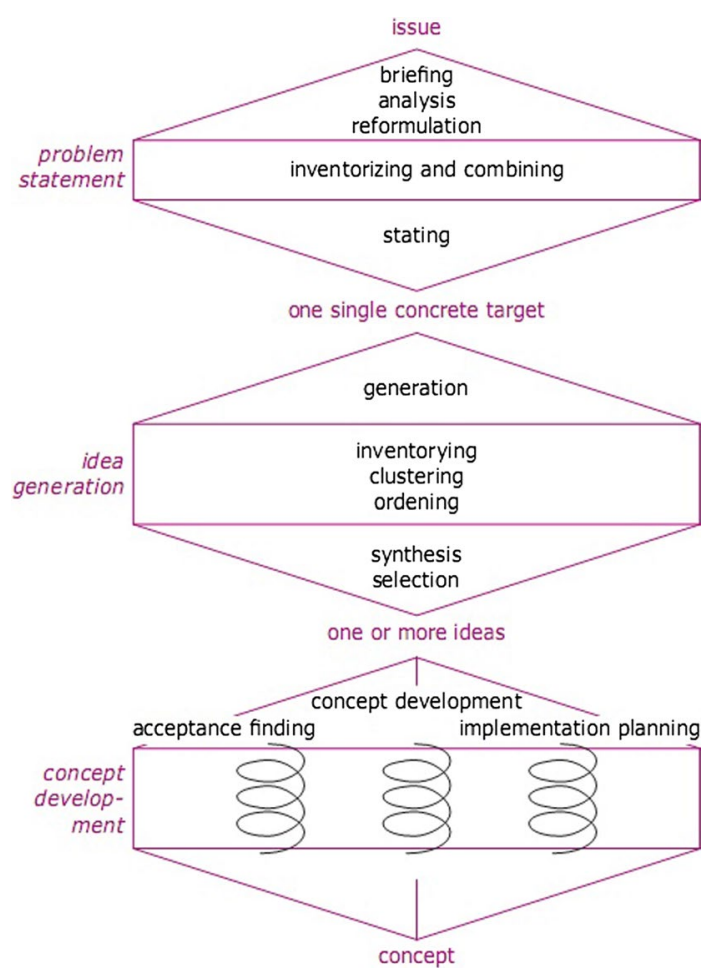




\section{Design fixation}

The repeated alternation of DT and CT during the concept development stage is not without effort, and can be easily stagnated by many factors. One of the factors hampering this alteration in the creative thinking processes is the occurrence of 'fixation'. In its most broad definition fixation can be described as a sort of mental block (Finke et al. 1992). It is a very common phenomenon which is not only limited to creative processes, but can occur in a wide variety of cognitive domains (Finke et al. 1992). Its occurrence in creative processes has been, and still is, researched quite extensively. Predominantly in relation to creative idea generation (Smith et al. 1993). One of the first well-known examples of fixation stems from research into creative problem-solving within the domain of psychology and is that of Duncker's candle problem (Duncker 1945). In the candle problem, subjects are expected to attach a candle to a vertical surface and light it without letting wax drip on the table surface by making use of a box of tacks and a book of matches. Fixation, or here called functional fixedness, is then observed through the inability of the subjects to produce alternate functions for the given objects in order to solve the problem.

Jansson and Smith (1991) were the first to conduct research into the fixation in the domain of engineering and design, in which they tested the effects of examples on creative idea generation. Their results showed that the examples shown to the subjects induced conformity within their designs. The fixated mindset of the subjects constrained their creative idea generation. Even when they were specifically told to diverge as much from the examples as possible the fixation effect still persisted. Additionally, one version of their experiment showed that even experienced designers fixate on attributes in the example designs, despite their clear undesirableness. Jansson and Smith (1991) refer to design fixation as "a blind, and sometimes counterproductive, adherence to a limited set of ideas in the design process". Purcell and Gero (1996) also note the aspect of premature commitment to a particular problem solution: “...the designer appears trapped by the characteristics of a possible solution that has been developed or an existing precedent solution". There are a number of causes that can contribute to the emerging of design fixation: example solutions, inspirational material, ill-defined problems, expertise or unfamiliarity with certain domain knowledge, previously generated ideas, feelings of ownership and it appears that even the will to be 'different' can cause design fixation (Jansson and Smith 1991; Moreno et al. 2015; Purcell and Gero 1996; Smith 2003).

Most research on design fixation focuses on the idea generation phase in the early stages of the design process. Specifically, the influence of external stimuli on creative idea generation, like example solutions and inspirational material, has been researched rather extensively. A literature review focussing on this type of design fixation by Vasconcelos and Crilly (2016), in which they highlight the similarities and differences between the different studies and suggest several recommendations, gives a good overview of its current state of the field (Vasconcelos and Crilly 2016). In a report summarizing the results from an international workshop focussed on the future of design fixation research, Crilly and Cardoso (2016) even propose a specific name for fixation on idea generation in the earlier phases, namely 'ideation fixation'. Further, they suggest several opportunities for future research, one of which is the occurrence of design fixation during later stages of the design process (Crilly and Cardoso 2016). Next section will introduce design fixation in relation to concept development. 


\section{Concept fixation}

Design fixation can also occur during the concept development stage of a design process. To clarify the difference between this type of fixation in relation to fixation in the idea generation phase, we propose the term 'concept fixation' to indicate this type of fixation. Concept fixation leaves the designer stuck in a certain train of thought, adhering to the current (possibly unfavourable) state of the design (idea). This adherence can range from small details to key features and components. Through it (sub)problems within the are idea easily overlooked and requirements are sooner thought to be already embodied within the design. Consequentially, success in developing a design idea then depends on one's ability to abandon this train of thought and generate alternative ones (Smith 1995). Only then the continuous alteration of DT and CT can continue through which an idea can be adjusted and elaborated on in order to embody all the design requirements and fully solve the problem at hand.

\section{Fixation in young novice designers}

In the context of design and technology education, design fixation is mainly researched in the design processes of university students. Yet there are examples of research into the occurrence of design fixation in secondary and primary education settings. Rather wellknown is the work of Nicholl and McLellan, who researched the phenomenon of design fixation in secondary design and technology (D\&T) students (ages 11-16). In their research, it was acknowledged by students and teachers alike that generating original ideas is difficult for the students. Many of the generated design ideas are derived from popular culture or examples shown by the teacher, since this is an easily accessible source of inspiration for them (McLellan and Nicholl 2009; Nicholl and Mclellan 2007a, b). As a result, many of the designs became stereotypical in nature, showing the ideation fixation-effect and exemplifying how thinking along the 'path-of-least-resistance' can influence a design (Ward 1994).

It also became apparent that students became fixated on the first idea that came to mind and that they were not motivated to think of multiple ideas. They did not understand the concept and the possibility of accepting or rejecting ideas. The students simply wanted to go with their first idea for which they had already worked out how to proceed. As one teacher stated in Nicholl and McLellan's research: "They get a fixed image, that's what I want to make. It's very hard to make them see that you can change and modify this. They're fixed, they think now that's what I want and that's what I'll do" (Nicholl and Mclellan 2007a, b). Here we see how the occurrence of concept fixation hampers the student's creative thinking processes. The students' fixation on the constructed image of the final design prevents them from further developing their idea. Since they already have an exact image of how the design will look and function their creative thinking is set to a halt. Their CT is hampered because they see no need to critically reflect on the state of their already 'perfect' design. As a consequence, they will also not explore alternative solutions for these sub-problems within the problem space (DT).

A case study by Luo (2015) found comparable results regarding design fixation during an engineering design project with primary school students aged 8 to 11 . Similar to the results of Nicholl and McLellan, these younger students fixated on popular culture, common features, and their first design ideas (Luo 2015). Although the distinction between 
ideation fixation and concept fixation is not made in these studies, the results show that both types of design fixation can occur from a young age.

\section{Identification of design fixation}

Currently, design fixation is mostly identified and studied indirectly by analysing design ideas, prototypes and artefacts when a design process has ended (Sio et al. 2015; Vasconcelos and Crilly 2016). Also in the classroom, design fixation is only assessed at the end of a design project through 'stereotypical' designs that are made by the children (Luo 2015; Nicholl and McLellan 2008; Nicholl and Mclellan 2007a, b). At that moment it is too late for the children avoid or overcome their fixation. Identifying fixation during the design process, instead of when the project has already ended, can transform the occurrence of design fixation into a learning process through which DT and CT can be practiced. For that reason, we want to find ways through which concept fixation can be identified during the concept development stage of a design process.

We expect that the analysis of conversations that take place about design ideas, prototypes and artefacts offers opportunities for the early detection of fixation during concept development. When designing in teams, talk is used as one of the main principles in constructing and developing design ideas. Through talk, a shared understanding of a design idea can be reached and agreements and compromises can be made (Fox-Turnbull 2018). We expect concept fixation to become visible through friction in the conversations in which the children designers show resistance towards external comments, suggestions and questions regarding the development of their design idea. There are, for instance, examples of students reacting 'negatively' to design feedback from their instructors and/or clients in order to keep the imagined construct of their design intact. We will introduce this in the following section.

\section{Design feedback sessions}

Feedback interventions, or design reviews, are common educational practice in design disciplines at university level (Goldschmidt et al. 2010; Yilmaz and Daly 2014) and can benefit the design process greatly (Crilly 2015). During these design reviews, the students communicate their design ideas, goals and expected user interactions in words, sketches and early models to the instructor, their peers and other stakeholders. They, in turn, react with questions and comments in order to get clarification on aspects of the design and the choices made. This feedback can encourage the students to take convergent or divergent paths in their design process (Cardoso et al. 2014; Yilmaz and Daly 2014, 2016), helping them with the development of their design idea.

When receiving feedback on their design there is always an inherent contradiction with which designers have to deal. As Crilly states, "Designers must remain open to the possibility that their ideas are limited or misdirected whilst also being persistent in developing their nascent ideas in the face of negative feedback" (Crilly 2015). When a designer is too persistent in developing an idea, fixation can emerge. Alternately, when a designer is too open to the possibility that something might be wrong with their ideas, it might be that many valuable ideas never get developed (Csikszentmihalyi 1999). So, in conversations a designer has to balance between openness and persistence. We presume that the tension that occurs in this balancing process can offer an opportunity to observe the occurrence of concept fixation. 
We expect this tension between openness and persistence to become visible through the manner in which the children react towards the design feedback that is posed. Research has for example shown that university students can react negatively towards feedback that asks for clarification of certain aspects of the design. As a result, they either end up being too descriptive (Cardoso et al. 2014) or become defensive and try even harder to convince everyone of the quality of their design (Cardella et al. 2014; Cummings et al. 2015). These types of interactions could inhibit a student's critical thinking processes, since they will not easily engage in reflective or evaluative thinking about the state of their idea when they feel they have to justify it.

\section{Research design}

Here we describe the results of an explorative case study within the design-based research project 'Co-Design with Kids: Early mastering of 21 st century skills'. In this project, scientific partners and partners from education and the industry developed a toolbox to conduct co-design sessions at primary schools. Within this research project we use a design-based research approach (Van Aken and Andriessen 2011), comprising a series of case studies with in-depth analysis using qualitative research methods. Here we present the first explorative case study, which is focussed on identifying and understanding the problem. Follow up cases will be directed towards developing possible solutions.

In this explorative case study, we facilitated a class of primary school children through a series of design sessions in which they created solutions to a real-life design challenge. Our goal was to identify the behaviour in the children that might indicate design fixation through the conversations that take place during the later stages of their design process. This is translated in the following explorative research question: How might concept fixation be expressed in the conversations of children during the concept development stage of the design process?

\section{Participants}

The design sessions took place at a primary school in the Netherlands in the area of ZuidHolland. The selection was based on the school's availability, their interest in design and technology education and a wish to experience a hands-on project giving new insights on how to implement design and technology within their curriculum. The participating school is, as they state, 'development-focused', meaning that umbrella themes are used to integrate different learning subjects over the course of a few weeks. The children are accustomed to collaborating in teams over a longer timeframe on a range of educational activities. In this study, one class participated over a period of 7 weeks in March and April of 2016. The class consisted of 24 children, ranging between 9 and 11 years old. The class of children had not participated in any design project prior to this one. The class was divided into six gender-mixed teams of four children by the teacher. When dividing the children into teams, the teacher was instructed to provide in each team a mix of different 'types' of children to create heterogeneous teams. As Kolb's learning styles are generally known by the teachers in the Netherlands through a simplified categorization, namely: dreamer, doer, thinker and decider, this was chosen as a guide to compose the teams. In addition to this, the teacher was asked specifically to pay attention to children's abilities to lead so that each team would, ideally, have one leader. 


\section{Design problem}

The children worked on solving a real-life problem which was made available by the HALO sports academy, which is part of The Hague University of Applied Sciences in the Netherlands. The design assignment was presented as follows: "Design a game, lesson or sports equipment for the gymnasium of the future that enables children with different participation motives to be physically active together". An example of different 'participation motives' is a child who enjoys a competitive component during physical activities and plays to win versus a child who enjoys playing together, regardless of winning or losing the game. A problem owner from the HALO, who acted as a client towards the children, introduced the design assignment to the children and was present during several of the design sessions to give feedback on the children's design ideas.

\section{Design sessions}

Over the course of 7 weeks, the children participated in teams in weekly design sessions of 90-120 minutes in which the teams were led through different diverging and converging stages. Table 1 presents an overview of the design sessions with the corresponding activities and how they related to each design phase. The connection to the design phases was based on a general representation of the design cycle that is used in primary schools in the Netherlands (Fig. 2). The design activities were based on tools and methods from the CPS tradition (Tassoul 2009) and design tools from the Delft Design Guide (van Boeijen et al. 2013). These methods and tools were transformed for use at primary school level in collaboration with the Science Hub Delft (Klapwijk \& Holla 2018), an organisation who develops educational material for primary schools to help develop research and design skills. The tools and methods were used during the design sessions to guide the teams through their design process. Examples of these tools and methods during the later stages of the design process, from session 4 onwards, were feedback interventions, prototyping and guidance from the facilitators through questions and suggestions. An overview of the design sessions can be found in Table 1. Although we expected these tools and methods to help the teams engage in DT and $\mathrm{CT}$ and develop their idea further during the later stages of their design process, we did not try to intentionally counteract or evoke concept fixation within the teams.

\section{Facilitation}

Three facilitators were present during the design sessions to facilitate the teams. Each facilitator was assigned two teams. Two facilitators, the first and second author, had a double role as researcher within the project. The client was present during sessions 1,4 and 7 in which he actively participated by explaining the design assignment (session 1) and giving feedback on the design ideas (session 4 and 7). During session 1, 4, 6 and 7, which were organised in a classroom setting, the teacher of the class was also present, yet did not guide the sessions.

\section{Setting}

During design session 2, 3 and 5, the teams were facilitated by their assigned facilitator in separate sessions in separate rooms. Session 1, 4, 6 and 7 took place in a classroom setting in which all teams participated simultaneously in one session. 


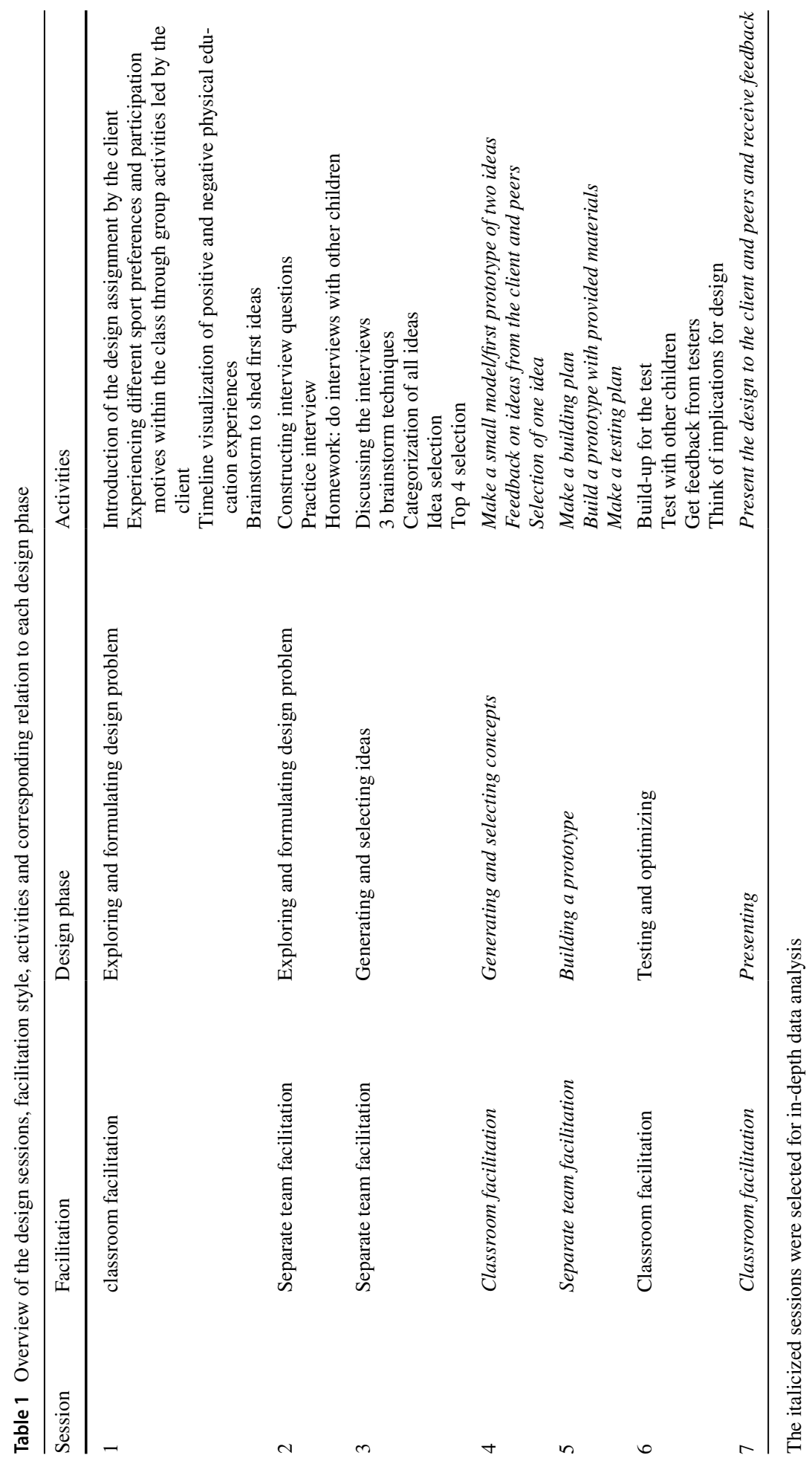




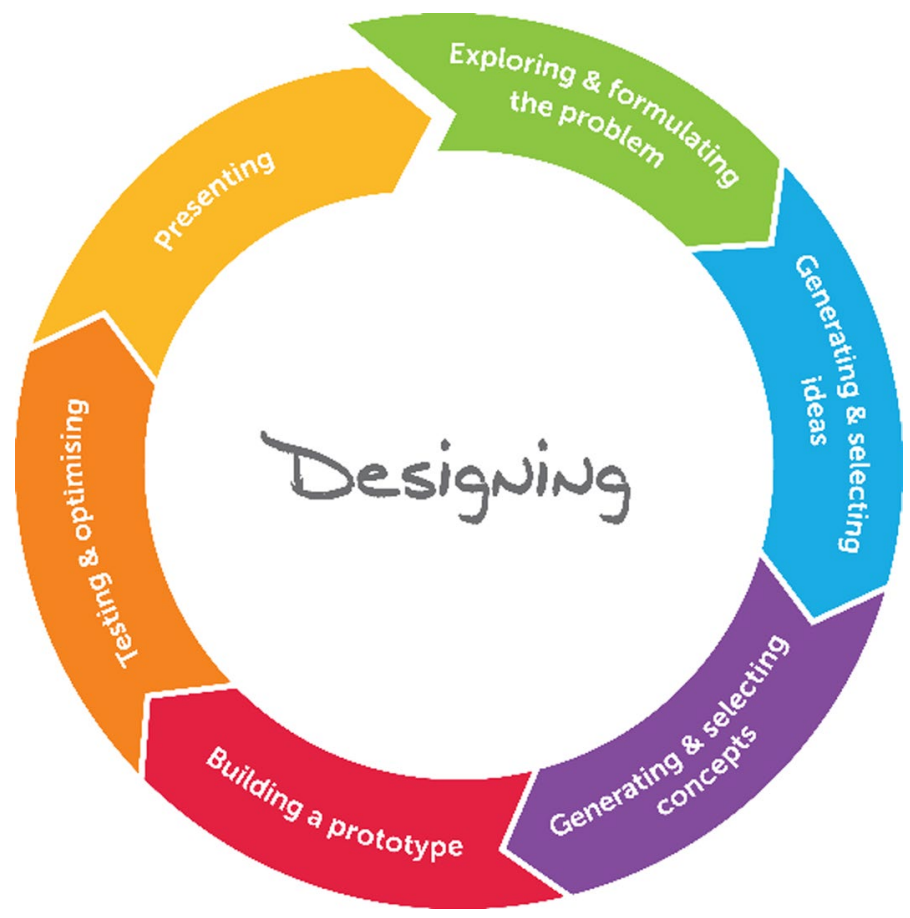

Fig. 2 Representation of the design cycle by the science hub. (Klapwijk 2017)

\section{Data collection}

The seven design sessions were audio and video recorded and the materials that the children produced during the sessions were photographed.

\section{Data analysis}

In order to analyse this stagnation in the development of the design ideas, we focused on the conversations that took place between the design team, their peers, the client and the facilitator during session 4, 5 and 7. During these sessions, the teams had selected their initial design idea and were expected to develop their idea further. In session 4 , the teams had selected their initial design idea and received feedback on their idea from their peers and the client. In session 5, the teams worked on building a prototype of their idea and in session 7 the teams presented their final design idea to the client and their peers and, again, received feedback. Two researchers transcribed the audio and video data of all the sessions, focusing on the discussions between the team members, their peers, facilitators and the client.

The purpose of our analysis was to look for possible indicators of concept fixation within the design teams through the conversations held with the client, peers and facilitators. This means that we looked for moments during which the children show adherence to their design idea (too much persistence) and a lack of openness to consider the 
questions, comments and suggestions posed about the state of the design ideas. The explorative nature of the case-study and limited previous research on design fixation in children's' design processes led us to conduct an inductive data-driven approach. This approach was similar to the work of Yilmaz and Daly (2016), who researched possible design feedback types and structures in the context of university students.

Firstly, the entire dataset was analysed through the constant comparative method (Glaser 2008; Glaser and Strauss 1967), to let recurring patterns indicating concept fixation emerge. This process of categorization was executed in three rounds by the same two researchers who also transcribed the audio and video data. During each categorization round, each researcher first individually selected sections of conversation indicating concept fixation. Afterwards, these individual selections were followed by sessions in which the researchers compared their individual categories. After three rounds, a consensus was reached on the final categorization and four categories were formed.

Secondly, we attempted to refine these categories by comparing them to the student response framework from Cummings et al. (2015) and Cardella et al. (2014). This framework was inductively constructed to analyse the responses of university design and engineering students towards design feedback they received. Although the framework does not aim to identify design fixation, we had strong suspicions that four codes from this framework could be an indication of concept fixation and therefore have similarities to the categories we found. These codes are: defend, ignore, denial and compensation. When comparing the codes to the categories, we noticed that the codes could be applied to the same sections of conversations as that of the categories found. Yet the codes grouped the types of concept fixation differently than the categories composed through the first analysis. For example, most of the sections could be coded with 'compensation', while the categories found by us distinguished more between the different manners in which concept fixation was expressed by the children. Therefore, the decision was made to keep the four categories found in the first analysis.

\section{Findings}

The preliminary findings of our analysis have been presented at the E\&PDE conference in 2017 (Schut et al. 2017). Based on the received feedback, we expanded the description of the results and incorporated more detail. Here, we will discuss several moments during which the children exhibited fixation on their design idea. This concept fixation was observed through the manner in which the teams responded during conversations with their peers, facilitators and the client in sessions 4, 5 and 7 . The response behaviours from the teams, indicating concept fixation, could ultimately be grouped into four categories. We named these categories: 'band-aids', 'already-in-there', 'question-notrelevant' and 'it's-not-possible'.

The following sections introduce these four categories through examples of conversations that took place between the children, facilitators and the client. Each section describes a category of response behaviour indicating concept fixation. The children that were part of the design team that the example focusses on are indicated as 'child' and, if necessary, a number. The children that were not part of the team are indicated as 'classmate' and, if necessary, a number. The client and facilitators are indicated as such. 


\section{Band-aids}

The first category of response behaviour that we will present is what we named 'bandaids'. There was a clear instance of the use of this type of response behaviour when the teams got feedback on their design idea during sessions 4 and 7. Band-aids are adjustments or additions to the design idea that leaves the core of the idea intact and do not present a possible valuable and relevant development. They are 'quick fixes' used to 'patch up' any flaws in the idea.

The 'everyone is different' example illustrates the band-aids response behaviour of one of the teams when they got feedback on their idea during the 7th session. In the example, the team had just presented their maze-game idea to their peers and the client. Their idea consisted of a maze in which different types of games can be played. The maze consisted of the equipment that is normally used during physical education classes. Figure 3 showcases images of the maze that the team built. The client started the conversation by asking a question related to one of the criteria present in the design question, namely, different participation motives.

\section{Everyone is different}

Client: Is it suitable for the different types of movers during physical education?

Child 1: In a sense, yes. If for example something is wrong, so you can't run or walk or something. Yeah, then. Uh. Or you can be there as a referee or you stand behind the line with the pawns. As a referee, you can check if the players don't cheat when they hide.

Client: Uh yes, ok. Uh. And what if I would like to stay very fit? If I would be a player and find that important.

Child 2: Yes, well then you just have to run many laps.

Client: Yes, so than I should make it more difficult for myself? Yes. Well, I guess that's possible. Ok.

In a sense, the children showed DT as they generated a number of options to make the maze-game suitable for different types of movers. Nevertheless, something can be said about the quality of the options mentioned. The proposed 'referee' idea, as well as the 'run many laps' idea, did not transform the idea of the maze-game to be intrinsically suitable for different types of movers. Both ideas made use of external systems that compensate for possible problems in the game itself. The difference between band-aids and idea
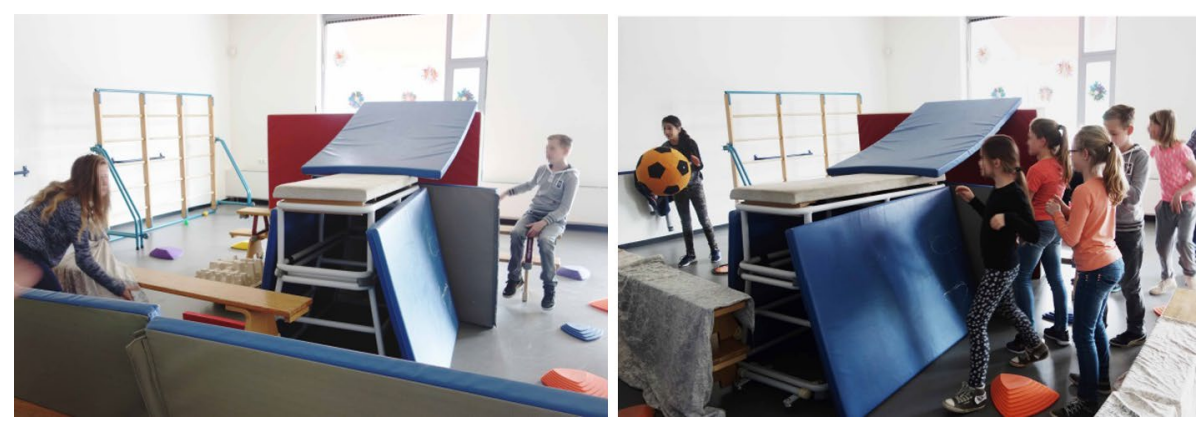

Fig. 3 Images of the maze-game idea. Both pictures illustrate the equipment used to build it. In the image on the right, the maze is being used by players to hide from another player holding a big ball 
development is that band-aids do not solve the actual problem within the idea and often lead to new problems. For example, the 'referee' idea appeared to solve the problem of a player not being able to run or walk. However, what if there are more players with the same problem? What about the players that cannot really run that hard or long to begin with? In addition, the player that is a referee does not really participate in the game, which could be quite demotivating. When children engage in band-aids response behaviour, the possibility for critical evaluation of the idea is set to a halt because the problem appears to be solved. As a consequence, the openness and reason to keep exploring alternative solutions is lost.

\section{Already in there}

Another category is 'already-in-there'. This type of response behaviour was detected during the 4th and 7th sessions during the moments when the teams got feedback from their peers and the client on their design idea. The already-in-there response entails that whatever others might detect as missing from the idea is, in fact, not missing since it was already present within the idea all along. However, that which is suddenly present within the idea according to the design team was never mentioned before the moment that others point it out as missing.

The 'it's all-in-one'-example is from the 4th session and illustrates a team engaging in already-in-there response behaviour. One of the teams presented their design idea about a device that combined a lot of sports in one object. Figure 4 showcases images of this design idea. On the spot, more sports were added to the idea. The additions that were mentioned in the conversation were not mentioned or discussed before within the team.

It's all-in-one

Classmate 1: What about if you want to do handball?

Child: You can do that as well with it.

Classmate 1: And if you like to play football?

Child: You can do that as well.

Classmate 2: So, it is all-in-one, and there is no korfball.

Child: Yes, there is korfball in there!

In a way, the conversation shows a development of the existing design idea through several elaborations. However, Child 2 is also deflecting the questions by stating that everything is
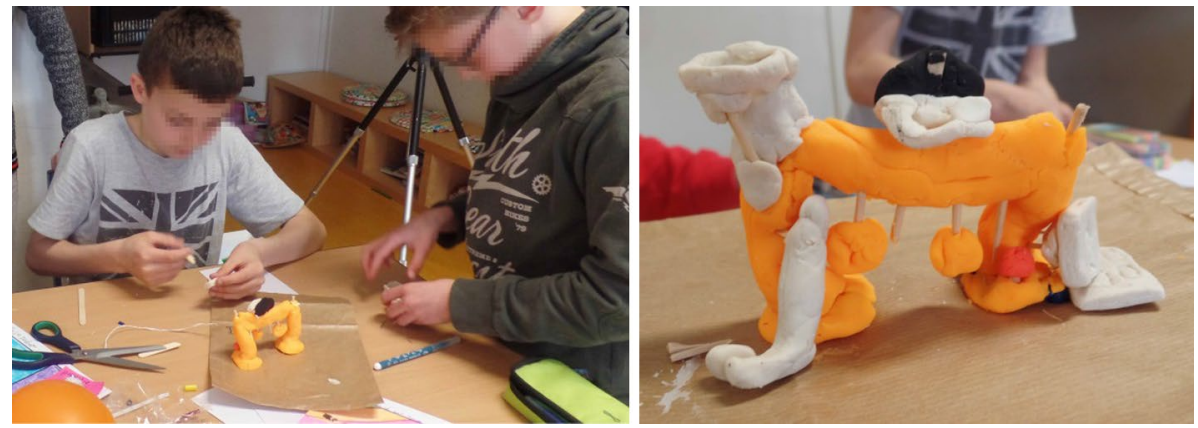

Fig. 4 Images of the all-in-one idea. The images illustrate a clay model that represents a new type of sport equipment with which many different types of sports can be played 
already present within the design. The team does not seem to use the feedback from others to evaluate the quality of their design and to see if any further development is needed. Feedback appears to be something that needs to be contradicted. Instead of something from which they can learn and which can help them to critically evaluate their design idea.

\section{Question not relevant}

'Question-not-relevant' is a type of response behaviour which, just like band-aids, peaked during the 4th and 7th sessions. Engaging in question-not-relevant response behaviour indicates that the feedback given is not relevant to the design idea. The following examples will illustrate this type of response behaviour. In both examples, the same team gets feedback on their idea, which they called b-games. Images of the idea are made visible in Fig. 5. The idea entails a sort of virtual reality dome in which different sports can be played. In the 'no friends needed' example below, a classmate suggests thinking about playing the designed game together with other children.

\section{No friends needed}

Classmate: How can you do this game with friends?

Child: Well. You don't have to do it with two people, you can also do it alone

Classmate: Okay...

The classmate's question stems from the design question given by the client, which mentions children being active together. One of the children from the design team answered that the game could be played alone, implying that no other players are needed. This left the classmate a bit puzzled. Since the classmate did not connect the feedback back to the design problem, it appeared to be a personal preference instead of a reference to the design criterion that was still missing. This could, in turn, explain the response behaviour of the team.

A second example, 'no handball included', showcases a different manner in which the question-not-relevant response was observed during the sessions. After presenting their idea, a classmate then asked a question about a technical aspect of the idea.

\section{No handball included}
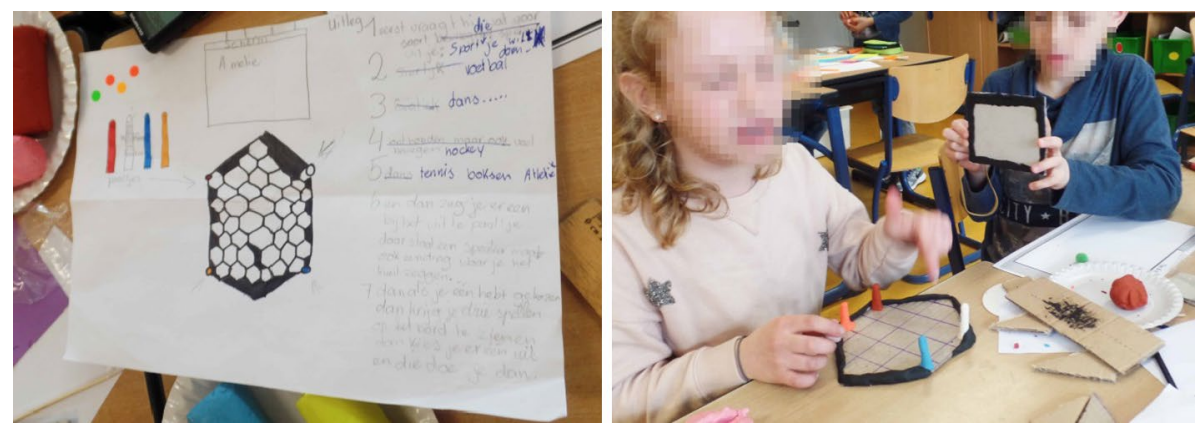

Fig. 5 Images of the $b$-games idea. The left image shows a sketch of the idea. The right image shows a clay model of the idea and two of the team members who demonstrate the model. One team member points at the virtual reality dome and the other team member holds up a screen, which is part of the dome 
Classmate: If you for example throw a ball during handball, then the computer can never know how fast you throw. Because he can also not...

Child: But we don't offer handball.

Here, the core of the question-how the speed of a ball thrown could be measured within the game-was ignored by the team. Instead, it was made clear that the sport used as a reference in the question was not part of their design idea. In both examples, engaging in question-not-relevant response behaviour enabled the team to ignore the core of the question and show that their idea still 'worked' by giving a deflecting answer.

\section{It is not possible}

The last category of response behaviour we will present in this paper is it's-not-possible. This response behaviour deems whatever is proposed or suggested as not feasible within the design idea. It was observed in session 5 and session 7. The following 'too light, too dark' example illustrates how a design team repeatedly engages in it's-not-possible response behaviour during the 5th session. In the example, the children of the team discussed a possible adjustment to their design idea, which was proposed by one of the team members, to make the design more interesting for the players.

Too light, too dark

Child 1: What if we make it (the gym) dark?

Child 2: That's impossible, the lights go on when you enter the gym.

Facilitator: Well, I'm sure we could turn off the lights.

Child 2: It is still too light because of the window.

Facilitator: We could cover the windows.

Child 1: Than it is too dark, children won't be able to see, that is dangerous.

After Child 2 rejected the idea as not possible, the facilitator tried to prompt the idea development by proposing several alternative solutions yet the team did not see the same possibilities as the facilitator and, in the end, even Child 1, who suggested the idea, rejected the idea altogether.

The next example illustrates a team engaging in the it's-not-possible response behaviour during the 7 th session.

\section{We can't do it}

Client: I might have a tip. Maybe you already know this, but I'm always looking for how you can make something easier or more difficult. That you can customize it for all players. Is that possible?

Child: Yeah, that was the idea you proposed, with the camera. That you think that someone is far away, but then they are very close. But we thought, we cannot really test that easily with the other children from our school.

Client: No, I understand. Also, I think that will mostly make it more thrilling.

The client appeared to try to get the team to think about possible solutions to meet, what was to him, an important design criterion: customizing the difficulty level for players. The team then referred back to an idea that the client had previously posed to them, which could be a solution to meet the design criteria, stating that they would not be able to execute an idea like this. Both examples show how the teams parried a DT process by stopping it before it even began, making it difficult for the facilitator and client to continue the line of questioning. 
When evaluating all four types of response behaviour, we conclude that engaging in these response behaviours allowed the teams to keep the core characteristics of their idea intact and unchanged, therefore leaving the teams fixated on the current state of their design idea.

\section{Discussion and conclusion}

The presence of design fixation during the children's design process is not a new phenomenon (Luo 2015; McLellan and Nicholl 2009; Nicholl and Mclellan 2007a, b). Yet where most work on design fixation analyses it by looking at the design ideas or produced artefacts, this research shows that it is also possible to signal design fixation through the conversations held in a classroom. Additionally, the focus lies on design fixation that occurs during concept development in the later stages of the design process, which we named: concept fixation. Four categories of response behaviours indicating concept fixation were uncovered during our analysis. Through several examples we aimed to illustrate these four behaviours. Table 2 gives an overview of the response behaviours that we uncovered and the effect each type can have on the creative thinking processes and, as a result, on the development of a design idea.

All four types of response behaviours allow the design teams to keep the core characteristics of their idea intact and unchanged, therefore leaving the teams fixated on the current state of their design idea. In the 'band-aids' and 'It's not possible' categories, the sub-problems within the design idea, or the opportunity proposed, is acknowledged. However, this feedback is also directly parried by either proposing invaluable and irrelevant adjustments or elaborations ('band-aids') or completely dismissing what is proposed as not feasible ('it's not possible'). In the other two categories, 'already in there' and 'question not relevant', the sub-problems within the design idea, or the opportunity proposed, is not acknowledged. The feedback that is given is either ignored by indicating it as irrelevant ('question not relevant') or dismissed by stating that any uncovered shortcoming or missing element was already present and working within the design idea ('already in there'). As a result of engaging in any of the described response behaviours, the feedback given is not used to critically evaluate the state of the design. We speculate that the absence of this critical evaluation let the teams to believe their designs were already in a 'complete state' and no sub-problems were present. This hampered their creative thinking by bringing continuous alteration of DT and CT to a halt. Since critical evaluation (CT) was absent, possible sub-problems within the designs were not uncovered. Consequently, there was no need to generate new ideas (DT) to elaborate or adjust the design.

Our results show that young novice designers (age 9-11) do not necessarily critically evaluate their own design in the concept development stage of the design process. Even though tools and methods were in place, like the feedback interventions, that are commonly thought to help idea development (Crilly 2015). This lack of evaluation of young novice designers is also observed in the field of linkography by Blom and Bogaers (2018). The field of linkography studies design cognition by analysing small increments of divergent and convergent thoughts. Here, Blom and Bogaers (2018) obtained results suggesting young novice designers (age 13-14) engage in limited critical convergent thoughts while designing compared to older novice designers, like university students. They found that the young designers proposed many new thoughts and ideas, but did not necessarily develop, evaluate or summarise them (Blom and 


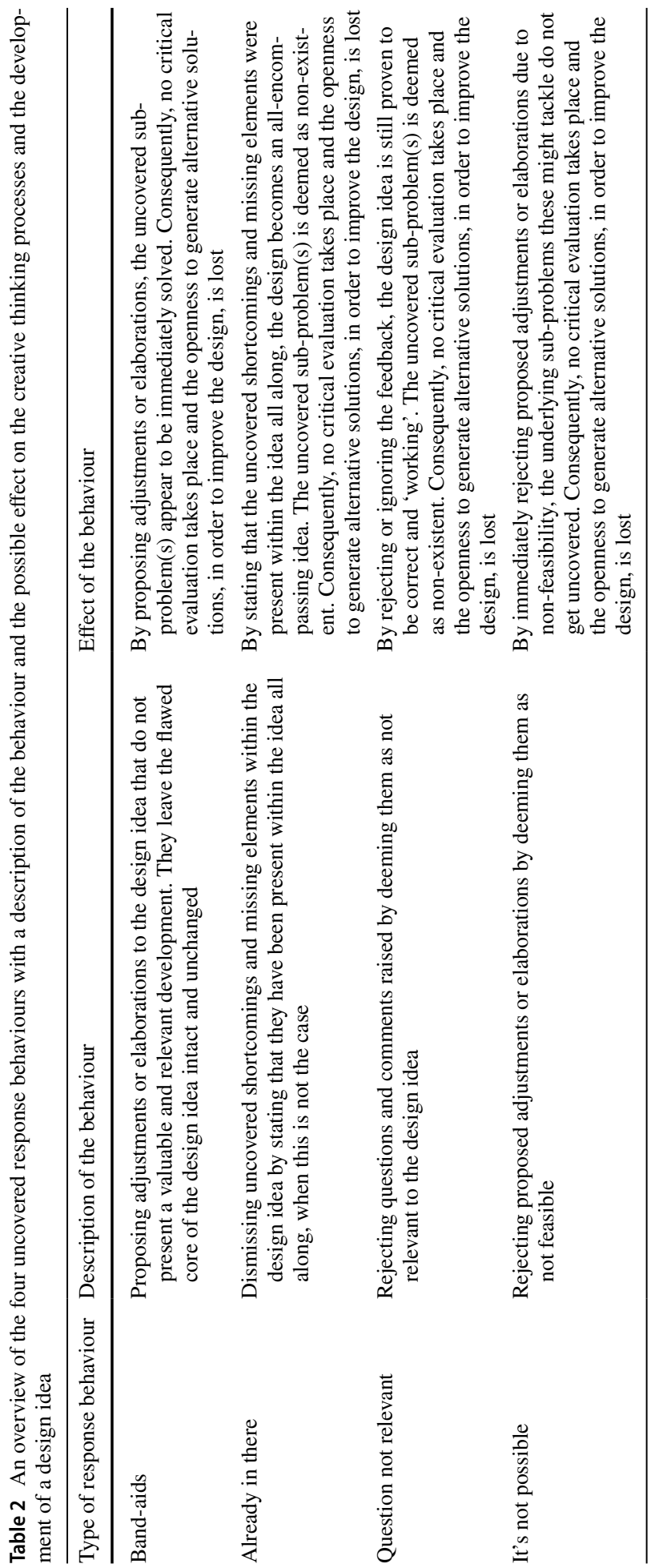


Bogaers 2018). In their research no tools or methods were used to guide the young designers through their design process, giving insight into their 'natural' thinking processes. Similar to ours, their results suggest that critical reflection does not happen 'naturally' in children.

In the context of D\&T education critical thinking is progressively seen as an important skill (Williams and Stables 2017). By practicing critical thinking and reflection within a design process the children will not only be able to better optimize the design they are working on, but it will also help them develop their personal critical view on design and technology in relation to this world. While designing they will uncover a wide range of questions: about ethics, economics, sustainability, usability, values, emotions and others, on what they plan to make and the impact it might have on its future users and surroundings. As Keirl (2007) puts it: "Critiquing is an excellent tool for arriving at the best defensible compromise" (Keirl 2007). The ability to think critically about one's own design can prove valuable in order to eliminate or overcome concept fixation.

In this study, the focus lied the early identification of concept fixation. Therefore, we did not explore the reasons why the design teams might have experienced this type of fixation during their design processes.

The parrying of feedback by the design teams suggests that they might have felt too much attachment to their design ideas, creating strong feelings of ownership. Research by Bear shows that too much ownership can lead people to only selectively adopt given feedback (Baer and Brown 2012). Their findings suggest that the nature of the proposed change in combination with the feeling of loss and the negative effect the person might feel directly influences whether they remain open to or resist suggestions for change. This phenomenon is also known as 'kill your darlings', which is a phrase that in some creative processes is used by a facilitator or team member to remind one that sometimes you just need to let go of an idea (Tassoul 2009). Following the research of Viswanathan and Linsey (2011) we can speculate that the early first prototypes that the children made during the 4th design session (see Table 1) might have created or enhanced any feelings of attachment to their design idea. Yet feelings of attachment and ownership that a designer might have towards their design ideas do not necessarily have a negative impact on idea development. They can, for instance, help develop promising ideas of which the potential might be more hidden in the beginning of the design process.

Furthermore, we assume that the type of feedback given might have been unfitting in some instances, therefore pushing the teams even more into a fixated mindset. Interventions and methods that give feedback are regarded by experienced designers as a means to counteract fixation and help idea development (Crilly 2015). Feedback has the ability to encourage a designer to take DT as well as CT paths during their design process (Cardoso et al. 2014; Yilmaz and Daly 2014, 2016). A designer has to develop the skills to be able to balance between remaining open to possible flaws within the design ideas, yet also persistent in developing a promising idea despite receiving negative feedback (Crilly 2015; Csikszentmihalyi 1999). Nevertheless, our results show that feedback on (intermediate) design ideas does not necessarily help young novice designers (children age 9-11) to develop their ideas. Specifically, their lack of critical evaluation left sub-problems within their design hidden and discarded the need and openness for new generative processes. This stagnated their creative thinking processes by hampering the continuous alternation of DT and CT, which ultimately effected the development of their designs. 


\section{Implications and future research}

The four response behaviours that we have uncovered and described are not meant to be a full overview of all possible types. We expect that there might be more response behaviours indicating concept fixation. Therefore, more research is needed on the conversations that take place during design processes, both inside and outside design teams. Not only to gain insight into response behaviours indicating concept fixation, but also those indicating success in balancing between openness and persistence. For now, we expect that the indicators we found-'band-aids', 'already taken care of', 'question not relevant' and 'it's not possible'-will be helpful in identifying concept fixation during the design process, especially in an educational context. The process of identification of fixation, and reflecting on it, creates awareness. This is considered as an important step by professional designers towards guarding oneself from fixation episodes in future projects, and thus being more creative (Crilly 2015).

For educators, this identification can lead to an adjustment in facilitation techniques in order to help children practice and enhance their CT and regain openness in the design process to start new DT processes. This aligns with suggestions from Nicholl and McLellan (2007a, b), who also believe that targeted intervention from the person facilitating is needed to prevent and/or overcome design fixation. In our future cases, we will focus on creating interventions to help children to become aware of concept fixation and stimulate their divergent and convergent thinking processes in order to ultimately avoid or overcome their fixated mindset. We expect that the development of children's critical thinking skills will play a central role within these interventions.

Acknowledgements The NWO/NRO project Co-design with Kids: Early Mastering of 21st Century Skills is funded under the HC21call (Number 409-15-212). Ethical clearance from the Ethics Committee (HREC, TU Delft) has been obtained. Informed participation consent was obtained from the parents. We thank the participating school staff and pupils.

Open Access This article is distributed under the terms of the Creative Commons Attribution 4.0 International License (http://creativecommons.org/licenses/by/4.0/), which permits unrestricted use, distribution, and reproduction in any medium, provided you give appropriate credit to the original author(s) and the source, provide a link to the Creative Commons license, and indicate if changes were made.

\section{References}

Amabile, T. M. (1996). Creativity in context: Update to the social psychology of creativity. Oxford: Westview Press.

Atkinson, S. (2000). Does the need for high levels of performance curtail the development of creativity in design and technology project work? International Journal of Technology and Design Education, 10(3), 255-281.

Baer, M., \& Brown, G. (2012). Blind in one eye: How psychological ownership of ideas affects the types of suggestions people adopt. Organizational Behavior and Human Decision Processes, 118(1), 60-71.

Barlex, D. (2007). Creativity in school design and technology in England: A discussion of influences. International Journal of Design Education, 17, 149-162.

Benson, C., \& Lawson, S. (Eds.). (2017). Teaching design and technology creatively (1st ed.). London: Routledge.

Benson, C., \& Lunt, J. (2011). We're creative on a friday afternoon: Investigating children's perceptions of their experience of design \& technology in relation to creativity. Journal of Science Education and Technology, 20(5), 679-687.

Blom, N., \& Bogaers, A. (2018). Using Linkography to investigate students' thinking and information use during a STEM task. International Journal of Technology and Design Education. https://doi. org/10.1007/s10798-018-9489-5. 
Cardella, M. E., Buzzanell, P. M., Cummings, A., Tolbert, D., \& Zoltowiski, C. B. (2014). A tale of two design contexts: Quantitative and qualitative explorations of student-instructor interactions amidst ambiguity. In DTRS 10: Design thinking research symposium.

Cardoso, C., Eris, O., Badke-schaub, P., \& Aurisicchio, M. (2014). Question asking in design reviews: how does inquiry facilitate the learning interaction? In DTRS 10: Design thinking research symposium.

Crilly, N. (2015). Fixation and creativity in concept development: The attitudes and practices of expert designers. Design Studies, 38, 54-91.

Crilly, N., \& Cardoso, C. (2016). Where next for research on fixation, inspiration and creativity in design ? Findings from an international workshop. Design Studies, 50, 1-38.

Cropley, A. J., \& Urban, K. K. (2000). Programs and strategies for nurturing creativity. In K. Heller, F. J. Monks, R. F. Subotnik, \& R. J. Sternberg (Eds.), International handbook of giftedness and talent (pp. 481-494). Oxford: Elsevier.

Cropley, D., \& Cropley, A. (2010). Recognizing and fostering creativity in technological design education. International Journal of Technology and Design Education, 20(3), 345-358.

Csikszentmihalyi, M. (1999). CREATIVITEIT: Over flow, schepping en ontdekking (dutch edition) (3rd ed.). Amsterdam: Uitgeverij Boom.

Cummings, A., Tolbert, D., Zoltowiski, C. B., Cardella, M. E., \& Buzzanell, P. M. (2015). A quantitative exploration of student-instructor interactions amidst ambiguity. In R. S. Adams \& J. A. Siddiqui (Eds.), Analyzing design review conversations (pp. 395-412). West Lafayette, IN: Purdue University Press.

Dorst, K. (2003). Understanding design. Amsterdam: BIS Publishers.

Duncker, K. (1945). On problem-solving. Psychological Monographs, 58(5), i-113.

Finke, R. A., Ward, T. B., \& Smith, S. M. (1992). Creative cognition: Theory, research and application. Cambridge: MIT Press.

Fox-Turnbull, W. (2018). Classroom interaction in technology education. In M. J. de Vries (Ed.), Handbook of technology education (1st ed., pp. 551-566). Berlin: Springer.

Glaser, B., \& Strauss, A. (1967). The discovery of grounded theory. Hawthorne, NY: Aldine Publishing Company.

Glaser, B. G. (2008). Conceptualization: On theory and theorizing using grounded theory. International Journal of Qualitative Methods, 1(2), 23-38.

Goldschmidt, G. (2014). Linkography: Unfolding the design process. Cambridge: MIT Press.

Goldschmidt, G. (2016). Linkographic evidence for concurrent divergent and convergent thinking in creative design. Creativity Research Journal, 28(2), 115-122.

Goldschmidt, G., Hochman, H., \& Dafni, I. (2010). The design studio crit: Teacher-student communication. Artificial Intelligence for Engineering Design, Analysis and Manufacturing: AIEDAM, 24(3), 285-302.

Greven, J., \& Letschert, J. (2006). Kerndoelen Primair Onderwijs. Ministerie van Onderwijs, Cultuur En Wetenschap, 1-84.

Guilford, J. (1987). Creativity research: Past, present and future. In S. G. Isaksen (Ed.), Frontiers of creativity research (1st ed., pp. 33-65). Buffalo, NY: Bearly Ltd.

Guilford, J. P. (1956). The structure of intellect. Psychological Bulletin, 53, 267-293.

Guilford, J. P. (1962). Factors that aid and hinder creativity. Teachers College Record, 63, 380-392.

Guilford, J. P. (1967). The nature of human intelligence. New York: McGraw-Hill.

Howard, T. J., Culley, S. J., \& Dekoninck, E. (2008). Describing the creative design process by the integration of engineering design and cognitive psychology literature. Design Studies, 29(2), 160-180.

Howard-Jones, P. A. (2002). A dual-state model of creative cognition for supporting strategies that foster creativity in the classroom. International Journal of Technology and Design Education, 12(3), 215-226.

Isaksen, S. G., Dorval, B. K., \& Treffinger, D. J. (2010). Creative approaches to problem solving; A framework for innovation and change. Creative approaches to problem solving: A framework for innovation and change (3rd ed.). Los Angeles: SAGE Publications.

Jansson, D. G., \& Smith, S. M. (1991). Design fixation. Design Studies, 12(1), 3-11.

Keirl, S. (2007). Critiquing in a democratics of design and technology education. In J. R. Dakers, W. J. Dow, \& M. J. De Vries (Eds.), Proceedings Pupils attitudes towards technology (PATT 18). Glasgow: Faculty of Education, University of Glasgow, pp. 306-312.

Klapwijk, R. (2017). Creativity in design. In C. Benson \& S. Lawson (Eds.), Teaching design and technology creatively (pp. 51-72). New York: Routledge.

Klapwijk, R., \& Holla, E. (2018). Leidraad onderzoekend en ontwerpend leren. Delft.

Lewis, T. (2005). Creativity_A framework for the design/problem solving discourse in technology education. Journal of Technology Education, 17(1), 35-52.

Lewis, T. (2009). Creativity in technology education: Providing children with glimpses of their inventive potential. International Journal of Technology and Design Education, 19(3), 255-268.

Luo, Y. (2015). Design fixation and cooperative learning in elementary engineering design project: A case study. International Electronic Journal of Elementary Education, 8(1), 601-613. 
McLellan, R., \& Nicholl, B. (2009). "If i was going to design a chair, the last thing i would look at is a chair": Product analysis and the causes of fixation in students' design work 11-16 years. International Journal of Technology and Design Education, 21(1), 71-92.

Mioduser, D., \& Kipperman, D. (2002). Evaluation/modification cycles in junior high students' technological problem solving. International Journal of Technology and Design Education, 12, 123-138.

Moreno, D. P., Yang, M. C., Hernández, A. A., Linsey, J. S., \& Wood, K. L. (2015). A step beyond to overcome design fixation: A design-by-analogy approach. In Design computing and cognition'14 (pp. 607-624). Cham: Springer.

Nicholl, B., \& Mclellan, R. (2007a). "Oh yeah, yeah you get a lot of love hearts. The year $9 \mathrm{~s}$ are notorious for love hearts. Everything is love hearts." Fixation in pupils' design and technology work (11-16 years). Design and Technology Education: An International Journal, 12(1), 34-44.

Nicholl, B., \& McLellan, R. (2007b). The contribution of product analysis to fixation in students' design and technology work. Linking Learning: DATA International Research Conference, 2007, 71-76.

Nicholl, B., \& McLellan, R. (2008). 'We're all in this game whether we like it or not to get a number of As to Cs., Design and technology teachers' struggles to implement creativity and performativity policies. British Educational Research Journal, 34(5), 585-600.

Purcell, A. T., \& Gero, J. S. (1996). Design and other types of fixation. Design Studies, 17(4), 363-383.

Rutland, M., \& Barlex, D. (2008). Perspectives on pupil creativity in design and technology in the lower secondary curriculum in England. International Journal of Technology and Design Education, 18, 139-165.

Schut, A., Van Doorn, F., \& Klapwijk, R. (2017). Creativity in children's design processes: identifying indicators of design fixation. In Engineering and product design education, proceedings.

Scott, G., Leritz, L. E., \& Mumford, M. D. (2004). The effectiveness of creativity training: A quantitative review. Creativity Research Journal, 16(4), 361-388.

Sio, U. N., Kotovsky, K., \& Cagan, J. (2015). Fixation or inspiration? A meta-analytic review of the role of examples on design processes. Design Studies, 39, 70-99.

Smith, S. M. (1995). Fixation, incubation, and insight in memory and creative thinking. In S. M. Smith, T. B. Ward, \& R. A. Finke (Eds.), The creative cognition approach (pp. 135-156). Cambridge: Massachusetts Institute of Technology.

Smith, S. M. (2003). The constraining effects of initial ideas. In P. B. Paulus \& B. A. Nijstad (Eds.), Group creativity: Innovation through collaboration (pp. 15-31). Oxford: Oxford University Press.

Smith, S. M., Ward, T. B., \& Schumacher, J. S. (1993). Constraining effects of examples in a creative generation task. Memory \& Cognition, 21(6), 837-845.

Tassoul, M. (2009). Creative facilitation (3rd ed.). Delft: VSSD.

Thijs, A., Fisser, P., \& Hoeven van der, M. (2014). 21e Eeuwse Vaardigheden in Het Curriculum Van Het Funderend Onderwijs. Enschede.

Van Aken, J., \& Andriessen, D. (Eds.). (2011). Handboek ontwerpgericht wetenschappelijk onderzoek: wetenschap met effect (1st edition). Bloom Lemma uitgevers.

van Boeijen, A. G. C., Daalhuizen, J. J., Zijlstra, J. J. M., \& van der Schoor, R. S. A. (2013). Delft design guide. Amsterdam: BIS Publishers.

Vasconcelos, L. A., \& Crilly, N. (2016). Inspiration and fixation: Questions, methods, findings, and challenges. Design Studies, 42, 1-32.

Viswanathan, V., \& Linsey, J. (2011). Design fixation in physical modeling: An investigation on the role of sunk cost. In Volume 9: 23rd international conference on design theory and methodology; 16th design for manufacturing and the life cycle conference. ASME, pp. 119-130.

Voogt, J., \& Roblin, N. P. (2012). A comparative analysis of international frameworks for 21 st century competences: Implications for national curriculum policies. Journal of Curriculum Studies, 44(3), 299-321.

Ward, T. B. (1994). Structured imagination: The role of category structure in exemplar generation. Cognitive Psychology, 27, 1-40.

Williams, P. J., \& Stables, K. (Eds.). (2017). Critique in design and technology education (1st ed.). Singapore: Springer.

Yilmaz, S., \& Daly, S. R. (2014). Influences of feedback interventions on student concept generation and development practices. In DTRS 10: Design Thinking Research Symposium.

Yilmaz, S., \& Daly, S. R. (2016). Feedback in concept development: Comparing design disciplines. Design Studies, 45, 137-158.

Publisher's Note Springer Nature remains neutral with regard to jurisdictional claims in published maps and institutional affiliations. 